\title{
Public Perceptions, Expectations, and Views of Community Pharmacy Practice in Kuwait
}

\author{
Abdelmoneim I. Awad ${ }^{\mathrm{a}}$ Altaf Al-Rasheedic Jacinthe Lemay ${ }^{\mathrm{b}}$
}

Departments of a Pharmacy Practice and b Pharmacology and Therapeutics, Faculty of Pharmacy, Kuwait University, and ${ }^{\mathrm{C} A l-A d a n}$ Hospital, Ministry of Health, Safat, Kuwait

\section{Significance of the Study}

- The current study indicates that respondents had an overall negative perception of community pharmacists in Kuwait, expressed moderate confidence and trust and moderate expectations about their role, and viewed the current community pharmacy services as slightly positive. They indicated a willingness to be provided with more information about the role that the community pharmacist plays in the health care of the society. These findings highlight the need for designing interventions targeting specific areas to advance pharmacy practices to meet the public's needs and improve its satisfaction in Kuwait.

\section{Keywords}

Community pharmacists · Community pharmacy ·

Pharmacy practice $\cdot$ Views $\cdot$ Perceptions $\cdot$ Kuwait

\begin{abstract}
Objectives: This study was designed to determine public patterns for use of community pharmacies, perceptions of pharmacists, confidence and trust in pharmacists, and expectations about the pharmacist's roles, and to explore the public views and satisfaction with the current pharmacy services. Subjects and Methods: A descriptive, cross-sectional survey was performed using a pretested self-administered questionnaire on a sample of 481 individuals selected using a 2-stage stratified cluster sampling design. Descriptive and multivariate logistic regression analyses were used for data analysis. $p<0.05$ was considered statistically significant. $\boldsymbol{R e}$ -
\end{abstract}

\begin{tabular}{ll}
\hline KARGER & $\begin{array}{l}\text { ( } 2017 \text { The Author(s) } \\
\text { Published by S. Karger AG, Basel }\end{array}$ \\
$\begin{array}{l}\text { E-Mail karger@karger.com } \\
\text { www.karger.com/mpp }\end{array}$ & $\begin{array}{l}\text { This is an Open Access article licensed under the Creative Commons } \\
\text { Attribution-NonCommercial-4.0 International License (CC BY-NC) } \\
\text { (http://www.karger.com/Services/OpenAccessLicense), applicable to } \\
\text { the online version of the article only. Usage and distribution for com- } \\
\text { mercial purposes requires written permission. }\end{array}$
\end{tabular}

sults: The most common reasons for visiting a pharmacy were to purchase medications (prescription: $n=338$ [78.1\%] and nonprescription: $n=296$ [68.4\%]). Of the 433 respondents, 87 believed that pharmacists had a good balance between health and business matters; regarding any drug-related problem, 229 (52.9\%) identified the physician as the first person to contact, followed by the pharmacist ( $n=140$; $32.3 \%) ; 255$ (58.9\%) agreed that they trust pharmacists, while 237 (54.8\%) agreed that pharmacists have the ability to answer drug- or disease-related questions. Of the 433 respondents, 236 (54.5\%) did not expect the pharmacist's role to include monitoring health progress to ensure safe and effective use of medications, and 258 (59.6\%) were satisfied with the current pharmacy services. Conclusion: The current study indicated that respondents had overall negative perceptions of community pharmacists, expressed moderate expectations of their role, and viewed the current pharmacy

Abdelmoneim I. Awad, B. Pharm, M. Pharm, PhD

Department of Pharmacy Practice, Faculty of Pharmacy, Kuwait University PO Box 24923

Safat 13110 (Kuwait)

E-Mail amoneim@hsc.edu.kw 
services as slightly positive. These findings highlight the need for designing multifaceted interventions targeting specific areas to advance the community pharmacy practice in Kuwait.

(c) 2017 The Author(s)

Published by S. Karger AG, Basel

\section{Introduction}

Community pharmacies are recognized as the most accessible health care settings due to the high volume of people who use their services [1]. Hence, community pharmacists are well positioned to help improve and promote health, educate patients about their diseases, advise on minor ailments, provide information about the appropriate use of medications and potential side effects, encourage adherence, and identify, resolve, and prevent drug therapy problems in collaboration with other health care providers [2]. There is substantial evidence to support the benefits of pharmaceutical care for patient clinical outcomes and health care costs $[3,4]$. Studies in developed countries have documented that the engagement of community pharmacists with an extended scope of practice could have significant public health implications [5, 6]. The pharmaceutical care process assumes the establishment of a meaningful therapeutic relationship between the patient and the pharmacist based on care, trust, effective communication, and collaboration to promote health, prevent disease, and ensure safe and effective medication therapy [7]. Fruitful endorsement of the pharmaceutical care practice in community pharmacies primarily depends on understanding the patient's view, perception, and satisfaction regarding the current pharmacy services and the professional role of pharmacists regarding all pharmaceutical care activities [8].

Several studies have been conducted worldwide to investigate the public view, perception, satisfaction, and attitude towards community pharmacy services [8-20], and in studies from the USA and Canada it was reported that customers were highly satisfied with community pharmacy services and had a positive impression of community pharmacists [9-11]. In European countries, consumers expressed a positive overall perception of community pharmacists and appreciated their role in the health care system [12-14]. In Taiwan, a study showed that about one third of the public trusted pharmacists and consulted them as first professionals for answers about the use of medications [15]. In contrast, studies conducted in the Middle Eastern region, i.e., United Arab Emir-

Public Views of Community Pharmacy

Practice ates (UAE), Iraq, Palestine, Saudi Arabia, and Qatar showed relatively negative attitude towards the current role of the community pharmacist and a poor understanding of the expanded new roles of community pharmacists $[8,16-20]$.

In the last few years, effort has been made in Kuwait to implement pharmaceutical care services to help improve patient health outcomes [21-23]. A crucial factor for a successful transition to the pharmaceutical care practice is understanding the opinion and satisfaction of the general population regarding the current community pharmacy services and the expanded new roles of the pharmacist [7]. However, when the patient and the pharmacist have distinct expectations regarding the pharmacist's role and pharmacy services, problems may arise. Hence, this study was performed to determine public patterns for the use of community pharmacies, perceptions of pharmacists, confidence and trust in pharmacists, and expectations about the pharmacist's roles. Furthermore, this works aims to explore public views and satisfaction with the current community pharmacy services, as well the need for future services.

\section{Subjects and Methods}

A descriptive, cross-sectional study was conducted in Kuwait during the period of January to May 2015. The study population consisted of public-sector employees at the Government Ministries of Kuwait. The Ministry of Health Ethics Committee of Kuwait approved this study. The sample size was determined by the Raosoft sample size calculator using a margin of error of 5\%, a confidence interval of $95 \%$, and a population size of 2,187,155 people aged $\geq 20$ years [24]. The minimum sample size estimated for the study was 385 . Assuming a response rate of $80 \%$, a larger sample size of 481 individuals was approached. A 2-stage stratified cluster sampling design was used for selection of the study population from the Government Ministries. Four hundred thirty-three individuals agreed to take part in this study and were given the questionnaires in hand; they completed them anonymously and these were collected after completion by one of the study investigators (A.A.-R.). They were assured of confidentiality and written informed consent was obtained. Their ages ranged from 21 to 63 years.

Previously validated surveys in Taiwan, UAE, Saudi Arabia, and Qatar $[15,16,19,20]$ were adapted for this study. The questionnaire was translated into Arabic by a health professional translator (Ideal Translation Center, Kuwait). It was back translated into English by Professor Ahmed Abdelrahman, Kuwait University, who is fluent in both English and Arabic languages. The accuracy and meaning of the translated versions, both forward and backward, were checked by the authors and 2 academic staff members fluent in English and Arabic, and recommended amendments where necessary were discussed before being finalized. Then, the survey was pretested on 20 subjects and refinements were made as

Med Princ Pract 2017;26:438-446 439 
Table 1. Characteristics of the study participants

\begin{tabular}{|c|c|}
\hline Characteristic & Frequency \\
\hline \multicolumn{2}{|l|}{ Age (years) } \\
\hline $20-29$ & $124(28.6)$ \\
\hline $30-39$ & $167(38.6)$ \\
\hline$\geq 40$ & $142(32.8)$ \\
\hline \multicolumn{2}{|l|}{ Gender } \\
\hline Male & $269(62.1)$ \\
\hline Female & $164(37.9)$ \\
\hline \multicolumn{2}{|l|}{ Nationality } \\
\hline Kuwaiti & $251(58.0)$ \\
\hline Non-Kuwaiti & $182(42.0)$ \\
\hline \multicolumn{2}{|l|}{ Marital status } \\
\hline Single $\mathrm{a}^{\mathrm{a}}$ & $97(22.4)$ \\
\hline Married & $336(77.6)$ \\
\hline \multicolumn{2}{|l|}{ Educational level } \\
\hline Low $^{\mathrm{b}}$ & $51(11.8)$ \\
\hline Intermediate $e^{c}$ & $121(27.9)$ \\
\hline High $^{\mathrm{d}}$ & $261(60.3)$ \\
\hline \multicolumn{2}{|l|}{ Residence (governorates) } \\
\hline Hawalli & $116(26.8)$ \\
\hline Al-Farwaniyah & $101(23.4)$ \\
\hline Al-Ahmadi & $83(19.2)$ \\
\hline Capital & $69(15.9)$ \\
\hline Mubarak Al-Kabeer & $40(9.2)$ \\
\hline Al-Jahra & $24(5.5)$ \\
\hline \multicolumn{2}{|l|}{ Monthly income } \\
\hline Less than KWD 500 (USD 1,640) & $106(24.5)$ \\
\hline KWD $500-1,000$ (USD $1,640-3,280)$ & $205(47.3)$ \\
\hline Greater than KWD 1,000 (USD 3,280) & $122(28.2)$ \\
\hline \multicolumn{2}{|l|}{ Personal health } \\
\hline Excellent & $196(45.3)$ \\
\hline Very good & $149(34.4)$ \\
\hline Good & $75(17.3)$ \\
\hline Fair & $13(3.0)$ \\
\hline
\end{tabular}

Values are presented as numbers (\%). The total number of participants is 433. ${ }^{\text {a }}$ Includes divorced and widowed individuals. b Completed secondary school. ${ }^{\mathrm{c}}$ Diploma. ${ }^{\mathrm{d}}$ Bachelor degree or postgraduate degree.

necessary so that the questionnaire could be understood. The pretested questionnaire consisted of 6 sections, and it contained both open- and closed-ended questions. The first section included 8 items that provided information on the demographic and other characteristics of respondents (Table 1). Section 2 consisted of 8 questions; 3 of these were to provide information about the patterns of visiting the community pharmacy and the remaining 5 were about the public perceptions of pharmacists (Table 2). The third section included 4 statements to explore the participant's confidence and trust in community pharmacists (Table 3 ). Section 4 included 12 statements to determine the respondent's expectations about the pharmacist's role (Table 4). The fifth section included 5 statements to identify the respondent's views of current community pharmacy services (Table 5), in addition to 1 question to determine the level of their satisfaction with current pharmacies services. Section 6 included 10 possible services to identify the need for extended community pharmacy services (Table 6) and 1 question to identify the need of the participants for more information about the role that pharmacists can play in the health care of the society.

\section{Statistical Analysis}

The obtained data were analyzed using the Statistical Package for Social Sciences (SPSS, version 23; SPSS, Chicago, IL, USA). The results were reported as percentages $(95 \% \mathrm{CI})$, means $\pm \mathrm{SD}$, or medians (IQR). The internal consistency of the statements in each section was accessed using Cornbach's a test. Factor analysis was used to evaluate the construct validly of the instrument. The rated scores and factor loading, which were used to determine items that belong to the group responses, are summarized in Tables 3-5. A scoring system was applied to measure the respondent's confidence and trust in community pharmacists, expectations about pharmacists' roles, and views of the current services offered by pharmacies. The score in each section was calculated as a continuous variable by summing the participant's number of appropriate responses to the statements. One point was awarded for each appropriate response (strongly agree or agree). The confidence and trust score was categorized into 3 levels: low, 0-1; moderate, 2-3; and high, 4 . The expectations score was categorized into 3 levels: low, 0-6; moderate, 7-9; and high, 10-12. The view score on current services offered by pharmacies was categorized into 3 levels: negative, $0-2$; slightly positive, 3 ; and highly positive, $4-5$. The association of respondents' characteristics with dependent variables was first evaluated using univariate logistic regression. All variables with $p<0.25$ in the univariate analysis were included in the multivariate logistic regression analysis to determine the factors that were independently associated with each of the dependent variables. Only the results of the multivariate logistic analysis are reported showing OR and 95\% CI. $p<0.05$ was considered statistically significant.

\section{Results}

The median age of the study population was 35 years (IQR 12). Of the 433 respondents, 269 (62.1\%) were males, 251 (58.0\%) were Kuwaiti nationals, and 261 (60.3\%) had a high education level. The detailed characteristics of the respondents are shown in Table 1. More than half of the respondents mentioned visiting community pharmacies at least once every few months $(n=236$; $54.5 \%)$. The most commonly offered reason for visiting a community pharmacy was to purchase prescription medications ( $n=338 ; 78.1 \%)$. Most respondents chose to visit a particular community pharmacy as it was close to their home or work place or a shopping mall $(n=359$; $82.9 \%$ ). One-third ( $n=146 ; 33.7 \%$; $95 \%$ CI $29.3-38.4$ ) of the respondents perceived community pharmacists as being interested in both health and business matters but felt they tended to be more concerned with business matters. 
Table 2. Respondents' patterns for visiting community pharmacies and their perceptions about community pharmacists

\begin{tabular}{|c|c|c|}
\hline Question & Frequency & $95 \%$ CI \\
\hline \multicolumn{3}{|l|}{ Frequency of visiting a community pharmacy } \\
\hline At least once every few months & $236(54.5)$ & $(49.7-59.3)$ \\
\hline Two to three times a month & $149(34.4)$ & $(30.0-39.1)$ \\
\hline Once or more a week & $27(6.2)$ & $(4.2-9.1)$ \\
\hline Once a year & $21(4.9)$ & $(3.1-7.4)$ \\
\hline \multicolumn{3}{|l|}{ Reason for visiting any community pharmacy } \\
\hline To purchase prescription medications & $338(78.1)$ & $(73.8-81.81)$ \\
\hline To purchase nonprescription medications & $296(68.4)$ & $(73.8-81.8)$ \\
\hline To purchase parapharmaceutical products, e.g., sunscreens, cosmetics, and baby care products & $223(51.5)$ & $(46.7-56.3)$ \\
\hline To ask for pharmacist advice & $201(46.4)$ & $(41.7-51.2)$ \\
\hline To purchase monitoring devices, e.g., blood pressure devices and blood glucose meters & $190(43.9)$ & $(39.2-48.7)$ \\
\hline To get general health information & $131(30.3)$ & $(26.0-34.9)$ \\
\hline To get first-aid information & $104(24.0)$ & $(20.1-28.4)$ \\
\hline \multicolumn{3}{|l|}{ Factors that influence the choice of any particular community pharmacy } \\
\hline Close to their home or work place or shopping mall & $359(82.9)$ & $(79.0-86.3)$ \\
\hline Convenient pharmacy opening hours & $304(70.2)$ & $(65.6-74.43)$ \\
\hline Pharmacist knowledge and ability to answer any drug- or disease-related question & $237(54.7)$ & $(49.9-59.5)$ \\
\hline Provision of a good range of products and services & $232(53.6)$ & $(48.8-58.3)$ \\
\hline Good and competitive prices & $192(44.3)$ & $(39.6-49.2)$ \\
\hline Confidentiality and privacy & $189(43.6)$ & $(38.9-48.5)$ \\
\hline Friendliness of the pharmacy staff & $187(43.2)$ & $(38.5-48.0)$ \\
\hline Attractive appearance of the pharmacy & $117(27.0)$ & $(23.0-31.5)$ \\
\hline \multicolumn{3}{|l|}{ Image of community pharmacists } \\
\hline \multicolumn{2}{|l|}{ They are interested in both health and business matters but tend to be more concerned with } & $(29.3-38.4)$ \\
\hline They know a lot about drugs and are concerned about and committed to caring for the public & $93(21.5)$ & $(17.8-25.7)$ \\
\hline They have a good balance between health and business matters & $87(20.1)$ & $(16.5-24.2)$ \\
\hline \multicolumn{3}{|l|}{ They are primarily business people who are more concerned with making money than with the } \\
\hline health of their patients & $73(16.9)$ & $(13.5-20.8)$ \\
\hline They are more concerned with the health of patients than with the business & $34(7.9)$ & $(5.6-10.9)$ \\
\hline \multicolumn{3}{|l|}{ First person to contact in case of any drug-related question or problem } \\
\hline Physician & $229(52.9)$ & $(48.1-57.7)$ \\
\hline Pharmacist & $140(32.3)$ & $(28.0-37.0)$ \\
\hline Family members or friends & $53(12.2)$ & $(9.4-15.8)$ \\
\hline Nurse & $6(1.4)$ & $(0.6-3.2)$ \\
\hline Others such as the internet & $5(1.2)$ & $(0.4-2.8)$ \\
\hline \multicolumn{3}{|l|}{ Barriers to consulting the pharmacist as the first person $(n=293)$} \\
\hline Physicians are more trusted than pharmacists & $217(74.1)$ & $(45.3-54.9)$ \\
\hline Lack of privacy in the pharmacy & $199(67.9)$ & $(62.2-73.2)$ \\
\hline Lack of awareness of the ability of the pharmacist to answer drug-related questions & $164(56.0)$ & $(50.1-61.7)$ \\
\hline Busyness of the pharmacists & $151(51.5)$ & $(45.7-57.4)$ \\
\hline Lack of the pharmacist's knowledge to answer drug-related questions & $98(33.4)$ & $(28.1-39.2)$ \\
\hline \multicolumn{3}{|l|}{ Reasons for approaching the pharmacist before the physician $(n=140)$} \\
\hline Pharmacists are more knowledgeable about the doses and side effects of medications & $102(72.8)$ & $(64.6-79.9)$ \\
\hline Treatment of minor health ailments, e.g., heartburn, constipation, headache, and muscle pain & $86(61.4)$ & $(52.8-69.4)$ \\
\hline No waiting time is required to see the pharmacist & $82(58.6)$ & $(49.9-66.7)$ \\
\hline The pharmacist consultation is free of charge & $80(57.1)$ & $(48.5-65.4)$ \\
\hline No appointment is needed to visit the pharmacy & $73(52.1)$ & $(43.6-60.6)$ \\
\hline \multicolumn{3}{|l|}{ Desirable qualities in a pharmacist } \\
\hline Honesty and professionalism & $349(80.6)$ & $(76.5-84.2)$ \\
\hline Knowledge about medications and diseases & $337(77.8)$ & $(73.6-81.6)$ \\
\hline Willingness to offer advice and answer any drug-or disease-related question & $319(73.7)$ & $(69.2-77.7)$ \\
\hline Good communication skills & $247(57.0)$ & $(52.2-61.7)$ \\
\hline Understanding of patients' concerns & $233(53.8)$ & $(49.0-58.6)$ \\
\hline
\end{tabular}

Values are presented as numbers (\%) unless otherwise stated. Results are in descending order according to percentage responses. The total number of respondents is 433 .

Public Views of Community Pharmacy Practice 
Table 3. Respondents' confidence and trust in community pharmacists

\begin{tabular}{|c|c|c|c|c|c|c|c|c|}
\hline Statement & $\begin{array}{l}\text { Strongly } \\
\text { disagree }\end{array}$ & Disagree & Neutral & Agree & $\begin{array}{l}\text { Strongly } \\
\text { agree }\end{array}$ & Mean $^{a}$ & $\begin{array}{l}\text { Median }^{\mathrm{a}} \\
\text { (IQR) }\end{array}$ & $\begin{array}{l}\text { Factor } \\
\text { loading }\end{array}$ \\
\hline $\begin{array}{l}\text { The community pharmacist always treats me } \\
\text { sincerely }\end{array}$ & $6(1.4)$ & $27(6.2)$ & $141(32.5)$ & $154(35.6)$ & $105(24.3)$ & $3.8 \pm 0.9$ & $4.0(1.5)$ & 0.827 \\
\hline I trust the community pharmacist & $10(2.3)$ & $23(5.3)$ & $145(33.5)$ & $171(39.5)$ & $84(19.4)$ & $3.7 \pm 0.9$ & $4(1.0)$ & 0.553 \\
\hline $\begin{array}{l}\text { The community pharmacist has the ability to } \\
\text { answer my questions regarding medication } \\
\text { use and disease treatment }\end{array}$ & $8(1.8)$ & $43(9.9)$ & $145(33.5)$ & $173(40)$ & $64(14.8)$ & $3.6 \pm 0.9$ & $4(1.0)$ & 0.791 \\
\hline $\begin{array}{l}\text { The community pharmacist is the first professional you } \\
\text { seek answers from when you have a problem with a } \\
\text { medication }\end{array}$ & $35(8.1)$ & $125(28.9)$ & $133(30.7)$ & $90(20.8)$ & $50(11.5)$ & $3.0 \pm 1.1$ & $3(2.0)$ & 0.684 \\
\hline
\end{tabular}

Values are presented as numbers (\%) or means \pm SD unless otherwise stated. Results are in descending order according to average percentage agreement. The total number of respondents is $433 .{ }^{\text {a }} 1$, strongly disagree; 2 , disagree; 3 , neutral; 4 , agree; and 5 , strongly agree.

Table 4. Respondents' expectations about the community pharmacist's role

\begin{tabular}{|c|c|c|c|c|c|c|c|c|}
\hline I expect the community pharmacist to & $\begin{array}{l}\text { Strongly } \\
\text { disagree }\end{array}$ & Disagree & Neutral & Agree & $\begin{array}{l}\text { Strongly } \\
\text { agree }\end{array}$ & Mean $^{\mathrm{a}}$ & $\begin{array}{l}\text { Median }^{\mathrm{a}} \\
\text { (IQR) }\end{array}$ & $\begin{array}{l}\text { Factor } \\
\text { loading }\end{array}$ \\
\hline $\begin{array}{l}\text { Counsel me about the directions for use of } \\
\text { medications }\end{array}$ & $12(2.8)$ & $6(1.4)$ & $41(9.5)$ & $195(45.0)$ & $179(41.3)$ & $4.2 \pm 0.9$ & $4(1.0)$ & 0.830 \\
\hline Answer my drug-related questions & $11(2.5)$ & $7(1.6)$ & $50(11.5)$ & $208(48.0)$ & $157(36.3)$ & $4.1 \pm 0.9$ & $4(1.0)$ & 0.817 \\
\hline $\begin{array}{l}\text { Advise me on minor ailments, e.g., } \\
\text { headache, heartburn, constipation, muscle } \\
\text { pain, and minor skin problems }\end{array}$ & $12(2.8)$ & $14(3.2)$ & $62(14.3)$ & $190(43.9)$ & $155(35.8)$ & $4.1 \pm 0.9$ & $4(1.0)$ & 0.756 \\
\hline $\begin{array}{l}\text { Counsel me about the medication's action and } \\
\text { indication }\end{array}$ & $21(4.8)$ & $13(3.0)$ & $55(12.7)$ & $181(41.8)$ & $163(37.6)$ & $4.0 \pm 1.0$ & $4(1.0)$ & 0.791 \\
\hline Label my medications & $20(4.6)$ & $26(6.0)$ & $57(13.2)$ & $149(34.4)$ & $181(41.8)$ & $4.0 \pm 1.1$ & $4(1.0)$ & 0.753 \\
\hline $\begin{array}{l}\text { Check my prescriptions for accuracy in terms } \\
\text { of drug name and dose }\end{array}$ & $11(2.5)$ & $17(3.9)$ & $77(17.8)$ & $179(41.3)$ & $149(34.4)$ & $4.0 \pm 1.0$ & $4(1.0)$ & 0.768 \\
\hline $\begin{array}{l}\text { Counsel me about the main adverse side effects } \\
\text { of my medications and how to avoid them } \\
\text { and about potential interactions with other } \\
\text { medicines }\end{array}$ & $17(3.9)$ & $21(4.8)$ & $75(17.3)$ & $162(37.4)$ & $158(36.5)$ & $4.0 \pm 1.0$ & $4(2.0)$ & 0.808 \\
\hline $\begin{array}{l}\text { Help me in selecting an over-the-counter or } \\
\text { parapharmaceutical product, e.g., baby } \\
\text { care product, hair products, and cosmetics }\end{array}$ & $16(3.7)$ & $26(6.0)$ & $81(18.7)$ & $180(41.6)$ & $130(30.0)$ & $3.9 \pm 1.0$ & $4(2.0)$ & 0.734 \\
\hline Counsel me about the disease that I am sufferring from & $20(4.6)$ & $25(5.8)$ & $100(23.1)$ & $172(39.7)$ & $116(26.8)$ & $3.8 \pm 1.0$ & $4(2.0)$ & 0.770 \\
\hline $\begin{array}{l}\text { Initiate a dialog with me or my physician } \\
\text { when necessary to obtain a sufficiently } \\
\text { detailed medication history }\end{array}$ & $23(5.3)$ & $37(8.5)$ & $127(29.3)$ & $137(31.6)$ & $109(25.2)$ & $3.6 \pm 1.0$ & $4(2.0)$ & 0.640 \\
\hline $\begin{array}{l}\text { Perform proper screening and monitoring for } \\
\text { specific health conditions and diseases, e.g., } \\
\text { measuring blood pressure, blood glucose, } \\
\text { and blood cholesterol }\end{array}$ & $45(10.4)$ & $65(15.0)$ & $86(19.9)$ & $127(29.3)$ & $110(25.4)$ & $3.4 \pm 1.3$ & $4(3.0)$ & 0.674 \\
\hline $\begin{array}{l}\text { Monitor my health progress to ensure the } \\
\text { safe and effective use of medications }\end{array}$ & $44(10.2)$ & $71(16.4)$ & $121(27.9)$ & $119(27.5)$ & $78(18.0)$ & $3.3 \pm 1.2$ & $3(2.0)$ & 0.648 \\
\hline
\end{tabular}

Values are presented as numbers (\%) or means \pm SD unless otherwise stated. Results are in descending order according to average percentage agreement. The total number of respondents is $433 .{ }^{\text {a }} 1$, strongly disagree; 2 , disagree; 3 , neutral; 4 , agree; and 5 , strongly agree. 
Table 5. Respondents' views of the current community pharmacy services

\begin{tabular}{|c|c|c|c|c|c|c|c|c|}
\hline Statement & $\begin{array}{l}\text { Strongly } \\
\text { disagree }\end{array}$ & Disagree & Neutral & Agree & $\begin{array}{l}\text { Strongly } \\
\text { agree }\end{array}$ & Mean & $\begin{array}{l}\text { Median }^{\mathrm{a}} \\
\text { (IQR) }\end{array}$ & $\begin{array}{l}\text { Factor } \\
\text { loading }\end{array}$ \\
\hline $\begin{array}{l}\text { When I am buying my prescription medication, } \\
\text { privacy concerning my prescription is main- } \\
\text { tained by the pharmacist }\end{array}$ & $20(4.6)$ & $30(6.9)$ & $107(24.7)$ & $165(38.1)$ & $111(25.6)$ & $3.7 \pm 1.1$ & $4(2.0)$ & 0.792 \\
\hline $\begin{array}{l}\text { When I am buying my prescription medication, } \\
\text { the pharmacist provides me with thorough } \\
\text { medication counseling and encourages me to } \\
\text { ask questions }\end{array}$ & $19(4.4)$ & $43(9.9)$ & $108(24.9)$ & $162(37.4)$ & $101(23.3)$ & $3.7 \pm 1.1$ & $4(1.0)$ & 0.850 \\
\hline $\begin{array}{l}\text { When I am in the pharmacy I feel totally at ease } \\
\text { about asking the pharmacist for advice }\end{array}$ & $24(5.5)$ & $31(7.2)$ & $116(26.8)$ & $169(39.0)$ & $93(21.5)$ & $3.6 \pm 1.1$ & $4(1.0)$ & 0.794 \\
\hline $\begin{array}{l}\text { When I go to the pharmacy with a problem, the } \\
\text { pharmacist gives me enough time to discuss } \\
\text { my problem and listens to me carefully }\end{array}$ & $34(7.9)$ & $47(10.9)$ & $113(26.1)$ & $161(37.2)$ & $78(18.0)$ & $3.5 \pm 1.1$ & $4(1.0)$ & 0.813 \\
\hline $\begin{array}{l}\text { When I go to the pharmacy to ask any drug- } \\
\text { related question, the pharmacist is knowledgeabl } \\
\text { enough and always ready to answermy questions }\end{array}$ & $17(4.0)$ & $30(6.9)$ & $150(34.6)$ & $178(41.1)$ & 58 (13.4) & $3.5 \pm 0.9$ & $4(1.0)$ & 0.612 \\
\hline
\end{tabular}

Table 6. Respondents' need for services to be provided in community pharmacies in the future

\begin{tabular}{lcc}
\hline Service & Frequency & 95\% CI \\
\hline $\begin{array}{l}\text { Drug information } \\
\text { Advice on minor illness ailments, e.g., headache, heartburn, constipation, muscle pain, and }\end{array}$ & $401(92.6)$ & $(89.6-94.8)$ \\
$\quad$ minor skin problems & $373(86.1)$ & $(82.4-89.2)$ \\
Screening services, e.g., blood pressure, blood glucose, blood cholesterol and body weight & & \\
$\quad$ measurements & $358(82.7)$ & $(78.7-86.1)$ \\
Communication with the doctor & $352(81.3)$ & $(77.2-84.8)$ \\
Advice on smoking cessation & $321(74.1)$ & $(69.7-78.1)$ \\
Medication therapy management (medication review) & $318(73.4)$ & $(69.7-78.1)$ \\
Advice on a healthy diet, exercise & $312(72.1)$ & $(67.5-76.2)$ \\
Estimation of the 10-year risk of developing type 2 diabetes and/or cardiovascular disease & $255(58.9)$ & $(54.1-63.5)$ \\
Maintenance of patients' medical records & $245(56.6)$ & $(51.8-61.3)$ \\
Injections and immunizations & $201(46.4)$ & $(41.7-51.2)$
\end{tabular}

Values are presented as numbers (\%) unless otherwise stated. Results are in descending order according to average percentage agreement. The total number of respondents is 433 .

For consultation about any drug-related problem or question, the physician was identified as the first person to contact ( $n=229 ; 52.9 \%$ ), followed by the pharmacist ( $n=140 ; 32.3 \%)$. The respondents' patterns for visiting community pharmacies and their perceptions about community pharmacists are presented in Table 2. There were significant associations between the choice of pharmacist as the first person to contact in case of any drugrelated question or problem and the independent vari- ables (gender and age). The choice of the pharmacist as the first person to contact was found to be more common among females than males $(p=0.008$; OR $=2.2 ; 95 \% \mathrm{CI}$ 1.2-3.9) and among those aged $\geq 40$ years compared to other age groups $(p=0.01$; OR $=5.7 ; 95 \%$ CI $1.5-10.6)$.

Cronbach's $a$ for the statements in the sections to determine confidence and trust in community pharmacists was 0.8 , that for expectations about the community pharmacists' roles was 0.93 , and that for views of current com- 
munity pharmacy services was 0.87 . The median score for confidence and trust in community pharmacists reflected moderate confidence/trust (i.e., 2.0 [IQR 2.0] out of a maximum score of 4 ). The distribution of responses to the statements about confidence and trust in community pharmacists is shown in Table 3. There were no significant associations between respondents' overall confidence and trust in community pharmacists and the independent variables $(p>0.05)$. The median expectation score of the participants reflected moderate expectations (i.e., 9.0 [IQR 4.5] out of a maximum score of 12). The respondents' expectations about the community pharmacist's role are presented in Table 4 . The logistic regression analysis revealed that 2 independent variables had a significant influence on the respondents' overall expectations about pharmacists' roles. Females had higher expectations about pharmacists' roles compared to males ( $p=$ $0.01 ; \mathrm{OR}=2.3 ; 95 \%$ CI 1.2-4.3). Respondents resident in Al-Jahra expressed lower expectations about pharmacists' roles compared to those in the other 5 governorates $(p=0.02 ; \mathrm{OR}=0.29 ; 95 \%$ CI $0.11-0.83)$.

The median score for views of the current community pharmacy services reflected slightly positive views (i.e., 3.0 [IQR 3.0] out of a maximum score of 5). There were no significant associations between respondents' views of current services and the independent variables $(p>0.05)$. The respondents' views on the current community pharmacy services are shown in Table 5. Of the 433 respondents, 258 (59.6\%; 95\% CI 54.8-64.2) reported that they were satisfied with the current pharmacy services. There were no significant associations between the respondents' level of satisfaction and the independent variables $(p>0.05)$. The respondents' need for services that they would most like to see offered in community pharmacies in the future are presented in Table 6. Of the 433 respondents, 405 (93.5\%; 95\% CI 90.7-95.6) indicated their willingness to be provided with more information about the role the community pharmacist can play in the health care of the society.

\section{Discussion}

In this study the respondents had overall negative perceptions of community pharmacists in Kuwait. There was no consensus among the respondents on the professional role of pharmacist in the health care system. Almost one third expressed that the pharmacist was the first person they contacted for medication-related problems. The majority of the participants were acquainted with the different roles of pharmacists, with the exception of pharma- ceutical care elements that involved taking the medication history, disease screening, and monitoring health progress to ensure safe and effective medications use. Concerns regarding the current services, as indicated by some respondents, were: lack of privacy, inadequate medication counseling, inadequate time for discussing and listening to customers, and that pharmacists were not knowledgeable enough or ready to answer their questions. In general, respondents had a positive attitude towards the provision of future services such as screening/ monitoring services for blood pressure, blood glucose, blood cholesterol, and advice on lifestyle modifications. The current results reveal that there was no consensus among respondents on the professional role of pharmacists in the health care system. Less than one quarter of the respondents perceived pharmacists as health care professionals who are concerned and committed to caring for the public and have a good balance between health and business matters. Only $7.9 \%$ of respondents perceived pharmacists as being more concerned with healthrelated matters. These findings confirm those reported in Qatar, Palestine, and Saudi Arabia [18-20]. The negative perceptions could be attributed to the way in which pharmacists approach and communicate with patients, which is of significant importance for the pharmacist's image and patient satisfaction [18]. Furthermore, community pharmacies are typically privately owned for-profit businesses and patients often perceive community pharmacists to be more oriented toward commercial matters rather than being focused on patient care and health care delivery $[8,16-20]$.

The finding that over half of the respondents indicated the physician as the first person to consult regarding medication-related issues, primarily because they had more trust in the physician's ability to answer their questions and counsel them, confirmed the earlier studies in Qatar, Saudi Arabia, and Palestine [18-20]. A probable explanation for this finding could be the society's traditional belief that physicians' knowledge and skills make them the dominant professionals in the health care system $[19,20]$. Also, it might be attributed to the fact that some respondents had previous poor experiences that discouraged them to consult with pharmacists as firstline professionals [19]. About half of the respondents expected the pharmacist's role to involve taking the medication history (56.8\%), disease screening (54.7\%), and monitoring health progress to ensure safe and effective use of medications (45.5\%), and this percentage was higher than that reported in Qatar [20]. These findings revealed that the public might not be aware of the capabilities of com-
444

Med Princ Pract 2017;26:438-446 DOI: $10.1159 / 000481662$
Awad/Al-Rasheedi/Lemay 
munity pharmacists and probably might be due to a lack of any opportunity to use these services since most community pharmacists in Kuwait have not provided these services before.

The findings revealed important concerns regarding the current community pharmacy services. Approximately two fifths of the respondents disagreed that privacy concerning their prescription is maintained by pharmacists, and $46 \%$ stated that a lack of privacy in the pharmacy prevented them from consulting the pharmacist first about drug- or disease-related questions. These findings underline the importance of community pharmacies having systems in place to ensure that patient information is protected and kept confidential and to create areas that allow for private discussions between patients and pharmacists. The finding that nearly two fifths of the respondents disagreed on the fact that pharmacists could provide them with thorough medication counseling and encourage them to ask questions was similar to that reported in Saudi Arabia [8] but the percentage was lower than those reported in Qatar and UAE $[16,20]$. A probable explanation could be that community pharmacists in Kuwait dispense medications with the understanding that patients are knowledgeable about their medications and diseases. The finding that about half of the respondents disagreed with the statement that the pharmacist could give them enough time to discuss their problems and listened to them carefully was higher than that reported in Saudi Arabia $[8,19]$ but lower than that in Qatar, UAE, and Palestine $[16,18,20]$. A probable explanation could be the lack of time as reported by pharmacists in Kuwait as a barrier to providing pharmaceutical care $[25,26]$. The last concern was that about half of the respondents disagreed that the pharmacist was knowledgeable enough and always ready to answer their questions, and this was lower than reported in Qatar and UAE [16, 20].

Respondents expressed a positive attitude in relation to the future services to be provided in the community pharmacy; this highlighted the need for an initiative to include these services in the community pharmacies of Kuwait, which are crucial for the development of collaboration between community pharmacists and primary health care providers [20,27].

Logistic regression analysis showed that females and older age groups were more likely to contact the pharmacist as the first person in case of any drug-related question or problem. Also, females reported high expectations while residents of Al-Jahra were found to have low expectations about pharmacists' roles. More qualitative research is needed to describe and understand these predictors.

Public Views of Community Pharmacy Practice

\section{Recommendations}

Based on the findings of this study, the following recommendations are made to advance the community pharmacy practice in Kuwait. These interventions should: (a) provide training and education through continuous professional development to community pharmacists to undertake expanded professional roles and to improve their communication with patients to strengthen the patient-pharmacist relationship; (b) create awareness among the general population about community pharmacists' clinical experience and their ability to provide medicine information and patient care services; and (c) employ more pharmacists if this will attract more customers by extended services provided by pharmacists.

The limitations of the present study include: a selection bias that might be due to overrepresentation of people with a higher educational level compared to the latest census data in Kuwait; lack of a representative sample due to difficulty approaching the public at their residential areas; using multistage stratified clustered sampling; and the nonverification of whether or not the responses were correct.

\section{Conclusions}

The current study indicates that the respondents had overall negative perceptions of community pharmacists in Kuwait. They expressed moderate confidence and trust in community pharmacists and moderate expectations about their role. The views on current community pharmacy services were slightly positive. They indicated their willingness to be provided with more information about the role that the community pharmacist could play in the health care of the society. The present findings highlight the need for continuing education programs to equip pharmacists with the appropriate knowledge and competencies to meet the ever-changing needs of the pharmacy practice. It is important to point out that there is an apparent need to raise public awareness about the knowledge, expertise, and role of community pharmacists as pharmaceutical care providers, and to create areas with more privacy to foster pharmacist-patient communication.

\section{Acknowledgement}

The authors would like to thank Prof. Ahmed Abdelrahman for his technical assistance.
Med Princ Pract 2017;26:438-446

DOI: $10.1159 / 000481662$ 


\section{References}

1 Jackson JK, Sweidan M, Spinks JM, et al: Public health - recognising the role of Australian pharmacists. J Pharm Pract Res 2004;34:290292.

2 Nkansah N, Mostovetsky O, Yu C, et al: Effect of outpatient pharmacists' non-dispensing roles on patient outcomes and prescribing patterns. Cochrane Database Syst Rev 2010; 7:CD000336.

3 Hepler CD, Strand LM: Opportunities and responsibilities in pharmaceutical care. Am J Hosp Pharm 1990;47:533-543.

4 Berenguer B, La Casa C, de la Matta MJ, et al: Pharmaceutical care: past, present and future. Curr Pharm Des 2004;10:3931-3946.

5 George PP, Molina JA, Cheah J, et al: The evolving role of the community pharmacist in chronic disease management - a literature review. Ann Acad Med Singapore 2010;39:861867.

6 Tsuyuki RT, Al Hamarneh YN, Jones CA, et al: The effectiveness of pharmacist interventions on cardiovascular risk: the multicenter randomized controlled RxEACH trial. J Am Coll Cardiol 2016;67:2846-2854.

7 American Pharmacists Association: Principles of practice for pharmaceutical care. http://www.pharmacist.com/principlespractice-pharmaceutical-care (accessed December 2, 2016).

8 Al-Arifi MN: Patients' perception, views and satisfaction with pharmacists' role as health care provider in community pharmacy setting at Riyadh, Saudi Arabia. Saudi Pharm J 2012;20:323-330.
9 Cerulli J: Patients' perceptions of independent community pharmacists. J Am Pharm Assoc (Wash) 2002;42:279-282.

10 Stergachis A, Maine LL, Brown L: The 2001 national pharmacy consumer survey. J Am Pharm Assoc (Wash) 2002;42:568-576.

11 Farris KB, Stenton SB, Samnani M, et al: How satisfied are your patients? CPJ 2000;10:3236.

12 Catic T, Jusufovic FI, Tabakovic V: Patient perception of community pharmacist in Bosnia and Herzegovina. Mater Sociomed 2013; 25:206-209.

13 Cavaco AM, Dias JP, Bates IP: Consumers' perceptions of community pharmacy in Portugal: a qualitative exploratory study. Pharm World Sci 2005;27:54-60.

14 Wirth F, Tabone F, Azzopardi LM, et al: Consumer perception of the community pharmacist and community pharmacy services in Malta. J Pharm Health Serv Res 2010;1:189_ 194.

15 Chen YC, Tarn YH, Kreling DH: Public views of community pharmacists in Taiwan. Int J Pharm Pract 2012;20:203-206.

16 Al Akshar S, Metwaly Z, Mohammed S: Patients' perception of community pharmacy practice in UAE: an overview. IOSR J Pharm 2014;4:8-14.

17 Ibrahim IR, Al Tukmagi HF, Wayyes A: Attitude of Iraqi society towards the role of community pharmacists. Inov Pharm 2013;4:110.

18 Khdour MR, Hallak HO: Societal perspectives on community pharmacy services in West Bank - Palestine. Pharm Pract (Granada) 2012;10:17-24.
19 Bawazir AS: Consumer attitudes towards community pharmacy services in Saudi Arabia. Int J Pharm Pract 2004;12:83-89.

20 El Hajj MS, Salem S, Mansoor H: Public's attitudes towards community pharmacy in Qatar: a pilot study. Patient Prefer Adherence 2011;5:405-422.

21 Awad A, Al-Ebrahim S, Abahussain E: Pharmaceutical care services in hospitals of $\mathrm{Ku}$ wait. J Pharm Pharm Sci 2006;9:149-157.

22 Katoue MG, Awad AI, Schwinghammer TL, et al: Pharmaceutical care in Kuwait: hospital pharmacists' perspectives. Int J Clin Pharm 2014;36:1170-1178.

23 Al Haqan AA, Al-Taweel DM, Awad A, et al: Pharmacists' attitudes and role in diabetes management in Kuwait. Med Princ Pract 2017;26:273-279.

24 Raosoft I: Raosoft sample size calculator. 2004. http://www.raosoft.com/samplesize. html (accessed December 25, 2016).

25 Awad A, Abahussain E: Health promotion and education activities of community pharmacists in Kuwait. Pharm World Sci 2010;32: 146-153.

26 Awad A, Waheedi M: Community Pharmacists role in obesity treatment in Kuwait: a cross-sectional study. BMC Public Health 2012;12:863-872.

27 Eades CE, Ferguson JS, O'Carroll RE: Public health in community pharmacy: a systematic review of pharmacist and consumer views. BMC Public Health 2011;11:582-595. 